\title{
Splenic metastasis in a bitch affected by an ovarian dysgerminoma - a case report
}

\author{
Filippo Spadola, Giovanna Lucrezia Costa, Marco Quartuccio, Marcello Musicò, \\ Claudia Interlandi, Santo Cristarella
}

University of Messina, Department of Veterinary Sciences, Messina, Italy

Received November 15, 2017

Accepted June 27, 2018

\begin{abstract}
Dysgerminomas are infrequent neoplasms resulting from undifferentiated germinal cells, mainly observed in the bitch. Our case describes for the first time a dysgerminoma related splenic metastasis in a bitch. A 14-year-old crossbred bitch was admitted at our facility with a 3-month history of irregular oestrous cycle, vulvar swelling, haemorrhagic vaginal discharge, lethargy and anorexia. Cytological examination showed the presence of superficial epithelial cells of the vaginal mucosa with a high degree of cornification. Vaginoscopy showed the typical pale and crenulated mucosal folds (oestrus). Haematological analysis indicated moderate anaemia and leukocytosis, and increased level of oestrogen. Ultrasound examination showed a mass located caudally to the kidney in the region of the right ovary. Abdominal and thoracic radiographs confirmed the findings and did not reveal metastases. Suspecting an ovarian tumour, we decided to perform a complete ovariohysterectomy. Once located, the right ovary presented an increased volume, irregular shape and reddish colour. Samples collected during the procedure were stained with haematoxylin and eosin and observed under optical microscope. The cells were characterized by a scant cytoplasm, a large vesicle type nucleus with coarsely granular chromatin and distinct cell borders. The neoplastic cells were remarkably similar to those of a testicular seminoma, allowing for the diagnosis of ovarian dysgerminoma. Two years after the ovariohysterectomy, the owner reported history of increased volume of the abdomen and lethargy. A second surgery was performed during which an irregular splenic mass was found. The morphological diagnosis was "splenic metastasis of dysgerminoma". To the authors' knowledge, dysgerminoma related splenic metastasis was never described in the bitch before.
\end{abstract}

Dog, splenectomy, seminoma, teratomas, teratocarcinomas, pseudo-Meigs'syndrome

Dysgerminomas are very infrequent neoplasms resulting from undifferentiated germinal cells (MacLachlan and Kennedy 2002). They are mainly observed in the bitch and represent $4-12 \%$ of ovarian tumours with a metastatic range between $10 \%$ and $30 \%$ (Dehner et al. 1970; Kennedy et al. 1998; Sforna et al. 2003 Schlafer and Miller 2007; Klein 2007; Novotny et al. 2011). Dysgerminoma associated metastases have been described in the mesenteric region and mediastinal lymph nodes of liver and kidneys, in the retroperitoneal area, in the abdominal serosa, and in the lungs (McEntee 2002; Novotny et al. 2011). Ovarian masses range from 2 to $30 \mathrm{~cm}$, with an average size of $9.5 \mathrm{~cm}$. They are usually broad nodular masses, mostly unilateral, whose growth results in increased volume and spherical or ovoid shape of the affected ovary (MacLachlan and Kennedy 2002; Park et al. 2008; Novotny et al. 2011). Bilateral dysgerminomas are extremely rare (Patnaik and Greenlee 1987; Rolim et al. 2010). When the mass is sectioned, a greyish, hard and homogeneous parenchyma is revealed. Haemorrhages, necrosis, and cysts are also common inside the dysgerminomas (Dehner et al. 1970; MacLachlan and Kennedy 2002). Only 10-20\% of dysgerminomas in dogs are malignant (McEntee 1990; Novotny et al. 2011). A case of simultaneous dysgerminoma in the right ovary and granulosa cell tumour in the left ovary was described by Oliveira et al. (2016). Sfartz

Address for correspondence:

Marco Quartuccio

Department of Veterinary Sciences

University of Messina

Phone: +393478866540

Polo Universitario Annunziata, 98149 Messina, Italy 
et al. (2015) and Kang et al. (2017) described a case of pseudo-Meigs' syndrome associated dysgerminoma, and a case of ovarian remnant syndrome associated dysgerminoma.

Ovarian tumours are extremely rare in cats. Gelberg and McEntee (1985) published a survey comprising 22 cases of ovarian tumours in cats including six cases of dysgerminomas. This study represents the widest survey regarding dysgerminomas in felines. Another case of feline dysgerminoma was published by Andrews et al. (1974).

The most common clinical signs reported in dysgerminomas are abdominal palpable mass, vaginal dripping and bleeding, polyuria, polydipsia, vomiting, weight loss, diarrhoea, lethargy, anorexia, and alopecia (Greenlee and Patnaik 1985; Jackson et al. 1985; Brazzell and Borjesson 2006; Novotny et al. 2011). Some patients presented cystic endometrium hyperplasia, pyometra and consistent oestrus. These signs are related with hormones over-production (Greenlee and Patnaik 1985; Jackson et al. 1985; Rolim et al. 2010; Novotny et al. 2011; Antonov et al. 2014). Our case study describes ovarian dysgerminoma associated metastasis in the spleen of a bitch.

\section{Case description}

A 14-year-old crossbred bitch, body weight $6 \mathrm{~kg}$, was admitted at the Veterinary Teaching Hospital (Department of Veterinary Sciences, Messina University, Messina, Italy) with a 3-month history of irregular oestrous cycle, vulvar swelling and haemorrhagic vaginal discharge. Lethargy and anorexia arose one week before the admission. No contraceptive drugs were administered.

After physical examination, a sterile swab was inserted for vaginal cytology into the vulva in the dorsal direction and advanced horizontally up to the cranial vagina. After rubbing (gently rubbing or rolling) the vaginal wall, the swab was removed and rolled (not smeared) on a microscope slide and stained with May-Grünwald Giemsa. The slides were evaluated under optical microscope at $\times 20$ magnification.

Vaginoscopy was performed using a rigid endoscope (TCI-Endoscope, length $43 \mathrm{~cm}$, Karl Storz, Germany). The vulvar labia were separated and the instrument was introduced at the craniodorsal angle to avoid the clitoris trench until the vestibule and vagina were visualized after distention of the vaginal mucosa with a flush of air.

A blood sample was obtained from the cephalic vein, and collected in tubes without anticoagulant. The obtained sample was sent to the laboratory for the complete blood cell counts, blood biochemical indicators and for the determination of progesterone and 17 beta-estradiol. Ultrasound examination of the abdomen was performed in lateral recumbency, using a scanner (MyLab ${ }^{\mathrm{TM}} 40 \mathrm{VET}$, Esaote, Genova, Italy) equipped with alinear (10 to 12-MHz) transducer. Abdominal X-ray examination (Univet 300HS, Multimage Srl, Italy) was performed on both dorso-ventral and lateral views.

Suspecting an ovarian tumour, we decided to perform a complete ovariohysterectomy. The patient was fastened for $12 \mathrm{~h}$ before the procedure. Intramuscular injections of tramadol hydrochloride $(2 \mathrm{mg} / \mathrm{kg})$ and acepromazine maleate $(0.05 \mathrm{mg} / \mathrm{kg})$ were used as premedication. The patient was induced with diazepam $(0.5 \mathrm{mg} / \mathrm{kg})$ and propofol $(3 \mathrm{mg} / \mathrm{kg})$ administered intravenously. After intubation, anaesthesia was maintained with isoflurane in $100 \%$ oxygen. After preparation for surgery, the bitch was placed in dorsal recumbency and laparotomy was performed accessing the abdomen through the linea alba. Once located, the right ovary presented an increased volume, irregular shape, and reddish colour. The left ovary and the uterus presented otherwise normal shape and size. No macroscopic metastases were detected in the other abdominal organs. Complete ovariohysterectomy was performed and the abdomen closed as standard.

Samples collected during the procedure were fixed in $10 \%$ buffered formalin solution, dehydrated in increasing concentrations of ethyl alcohol, cleared in xylene and embedded 
in paraffin wax. Sections of the samples $(5$ to $6 \mu \mathrm{m})$ were stained with haematoxylin and eosin and observed under optical microscope.

Two years after the ovariohysterectomy, the owner reported history of increased volume of the abdomen and lethargy. Ultrasound and radiological examinations, and a second surgical procedure were performed (repeating the same protocol). Histological diagnosis was performed repeating the same protocol as the first time.

\section{Results}

Physical examination revealed a swollen vulva with haemorrhagic vaginal discharge. Upon palpation, the abdomen was found extremely sensitive, and a nodular mass was detected in the cranial quadrant.

The cytological examination showed the presence of superficial epithelial cells of the vaginal mucosa with a high degree of cornification (70-80\%). Vaginoscopy showed the typical pale and crenulated mucosal folds (oestrus). Haematological analysis indicated moderate anaemia and leukocytosis (haematocrit: 25.7\%, haemoglobin: $11.90 \mathrm{~g} / \mathrm{dl}$, red blood cells: $4.37 \times 10^{6} / \mu 1$, white blood cells: $\left.21.60 \times 10^{3} / \mu 1\right)$. Endocrine evaluation showed alterations in sexual steroid levels with increases in oestrogen [progesterone $(\mathrm{P} 4)=2.93 \mathrm{ng} / \mathrm{ml}, 17$ beta-estradiol $(\mathrm{E} 2)=82.3 \mathrm{pg} / \mathrm{ml}]$

The first ultrasound examination showed a "complex mass" located caudally to the kidney in the region of the right ovary. The mass was $7 \times 4.5 \mathrm{~cm}$ in size with several cavities. The left ovary was normal in appearance and $2.5 \mathrm{~cm}$ in diameter. The uterine horns presented moderate hyperplastic endometrium and no intraluminal secretion. Abdominal and thoracic radiographs confirmed the findings and did not reveal metastases.

The first gross examination revealed an enlargement $(8 \times 7 \times 3.5 \mathrm{~cm})$ of the right ovary. The enlarged right ovary was dark-reddish, multinodular in shape and firm to the section. The left ovary was normal and presented three corpora lutea. The uterine mucosa presented a number of endometrial cysts of $0.5 \mathrm{~cm}$ diameter and small areas of ecchymosis.

The first microscopic study highlighted the presence of sheets and cords of polygonal germ cell looking tumour cells. The cells were characterized by a scant cytoplasm, a large vesicle type nucleus with coarsely granular chromatin and distinct cell borders. The neoplastic cells were remarkably similar to those of a testicular seminoma, allowing for the diagnosis of ovarian dysgerminoma. No macro metastatic areas were found.

One week after the procedure, complete remission of clinical symptoms was found and the animal showed a good health condition; the vulva was reduced in size. Six months later another search for metastasis was performed through radiographic examination of the thoracic cavity. Ultrasonography evaluation of the abdominal cavity, mesenteric lymph nodes, kidneys, liver, pancreas, spleen, and urinary bladder was performed as well.

Two years later the ultrasound examination revealed the presence of a mass in the spleen. This finding was confirmed by radiography.

During the second surgical procedure an irregular splenic mass was found. The mass was $15 \times 10 \mathrm{~cm}$ in size, highly vascularized and contained by a large omentum. The splenic tissue showed multiple whitish and soft nodular lesions. The nodules ranged from 3 to $1.5 \mathrm{~mm}$, they were smooth and surrounded by fat tissue.

Microscopically, the splenic tissue was substituted by infiltrated neoplastic cells upsetting the physiological architecture of the organ. The neoplasm was composed of round cells organized in thick layers, and divided by fibrous tissue; their margins were distinct, with an average relation between the nucleus and cytoplasm. The cytoplasm was slightly basophil and homogeneous. The nuclei were vesicular, dysmetric and centrally located. Anisocytosis and anisocaryosis could be observed, together with numerous atypical and multipolar mitotic figures ( $0-3$ per high power field). Multifocal areas of necrosis were also 
observed (Plate II, Fig.1). The normal splenic tissue was extremely reduced and marginal. Numbers of neoplastic embolisms were detected. There were no lymph nodal structures. The morphological diagnosis was "splenic metastasis of dysgerminoma".

After one year of follow-up, no metastasis was diagnosed.

\section{Discussion}

The described findings show a highly invasive neoplasm with severe atypia. The dysgerminoma is an ovarian neoplasm generating from germinal gonadic cells; this tumour represents the female equivalent of the male seminoma (Dehner et al. 1970; Kennedy et al. 1998; Sforna et al. 2003; Schlafer and Miller 2007; Klein 2007; Novotny et al. 2011). The dysgerminoma is generally regarded as a malignant neoplasm, even though metastases are rare. Dysgerminoma related metastasis was described in the mesentery, in the mediastinal lymph-nodes, and in several abdominal organs, such as liver and kidney, in the intestinal mucosa and in the lungs by McEntee (2002) and Novotny et al. (2011). To the authors' knowledge, splenic metastasis related to dysgerminoma was never described in the bitch before. This clinical case can, therefore, enrich the literature regarding canine oncology. It is relevant to point out that the metastasis showed up only two years after the primary neoplasm was found. The metastasis generated with no clinical signs. No new lesions were found one year after the removal of the metastasis.

\section{References}

Andrews EJ, Stookey JL, Helland DR \& Slaughter LJ 1974: A histopathological study of canine and feline ovarian dysgerminomas. Can J Comp Med 38: 85-89

Antonov A, Fasulkov I, Simeonov RA 2014: Clinical case of unilateral ovarian dysgerminoma and pyometra in a bitch. Mac Vet Rev 37: 179-183

Brazzell JL, Borjesson DL 2006. Intra-abdominal mass aspirate from an alopecic dog. Vet Clin Pat 35: 259-262

Dehner LP, Norris HJ, Garner FM, Taylor HB 1970: Comparative pathology of ovarian neoplasms. III. Germ cell tumours of canine, bovine, feline, rodent and human species. J Comp Pat 80: 299-310

Gelberg HB, McEntee K 1985: Feline ovarian neoplasms. Vet Pathol 22: 572-576

Greenlee PG, Patnaik AK 1985: Canine ovarian tumors of germ cell origin. Vet Pathol 22: 117-122

Jackson ML, Mills JHL, Fowler JD 1985: Ovarian dysgerminoma in a bitch. Can Vet J 26: 285-287

Kang MH, Min SH, Choi YK, Park HM 2017: Management of ovarian dysgerminoma associated with pseudoMeigs's syndrome in a dog. Pak Vet J 37:111-113

Kennedy PC, Cullen JM, Edwards JF, Goldschmidt MH, Larsen S, Munson L, Nielsen S 1998: Histological classification of tumors of the genital system of domestic animals. World Health Organization, Washington D.C. 4: 17-19

Klein MK 2007: Tumors of the female reproductive system. In Withrow SJ, Vail DM (Eds): Small Animal Clinical Oncology. $4^{\text {th }}$ edn. St. Louis: Saunders Elsevier, pp 610-618

MacLachlan NJ, Kennedy PC 2002: Tumors of the genital systems. In Meuten DJ (Ed): Tumors in Domestic Animals. $4^{\text {th }}$ edn. Iowa State Press, Ames, IA, pp. 547-573

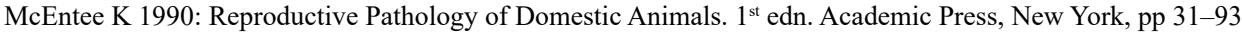

McEntee M 2002: Reproductive oncology. Clinical Techniques. Small An Pract 17: 133-149

Novotny R, Vitasek R, Bartoskova A 2011: Ovarian dysgerminoma with retroperitoneal metastases in a bitch: A case report. Vet Med-Czech 56: 140-144

Oliveira AR, Flecher MC, Jabour FF, Souza TD, Hardt I, Vieira FT, Rassele AC, Vicente GC, Machado FM 2016: Dysgerminoma and granulosa cell tumor in a bitch. Braz J Vet Pathol 9: 31-33

Park JK, Goo MJ, Hong IH, Ki MR, Han JY, Jeong KS 2008: Immunohistochemistry diagnosis of an ovarian dysgerminoma in one bitch. Reprod Domest Anim 44: 855-858

Patnaik AK, Greenlee PG 1987: Canine ovarian neoplasms: a clinicopathologic study of 71 cases including histology of 12 granulosa cell tumors. Vet Pathol 24: 509-514

Rolim VM, Pinto TM, Lopes LMA, Sonne L, Oliveira EC, Almeida PR, Beck CAC, Driemeier D 2010: Bilateral dysgerminoma and cystic endometrial hyperplasia with pyometra in bitch. Acta Sci Vet 38: 337-340

Schlafer D, Miller R 2007: Female genital system: neoplastic diseases of the ovary. In Maxie MG (Ed.): Jubb, Kennedy, and Palmer's Pathology of Domestic Animals. $5^{\text {th }}$ edn, Saunders Elsevier, Edinborough, UK, pp 429-564 
Sfartz I, Drugociu D, Roșca P, Ibănescu I, Crivei I 2015: Dysgerminoma, pyometra of the stump and mammary carcinoma in a female dog with ovarian remnant syndrome-case study. Bulletin UASVM Veterinary Medicine 72: $283-287$

Sforna M, Brachelente C, Lepri E, Mechelli L 2003: Canine ovarian tumours: A retrospective study of 49 cases. Vet Res Comm 27 (Suppl 1): 359-361 
Plate II

Spadola F. et al.: Splenic metastasis ... pp. 219-223

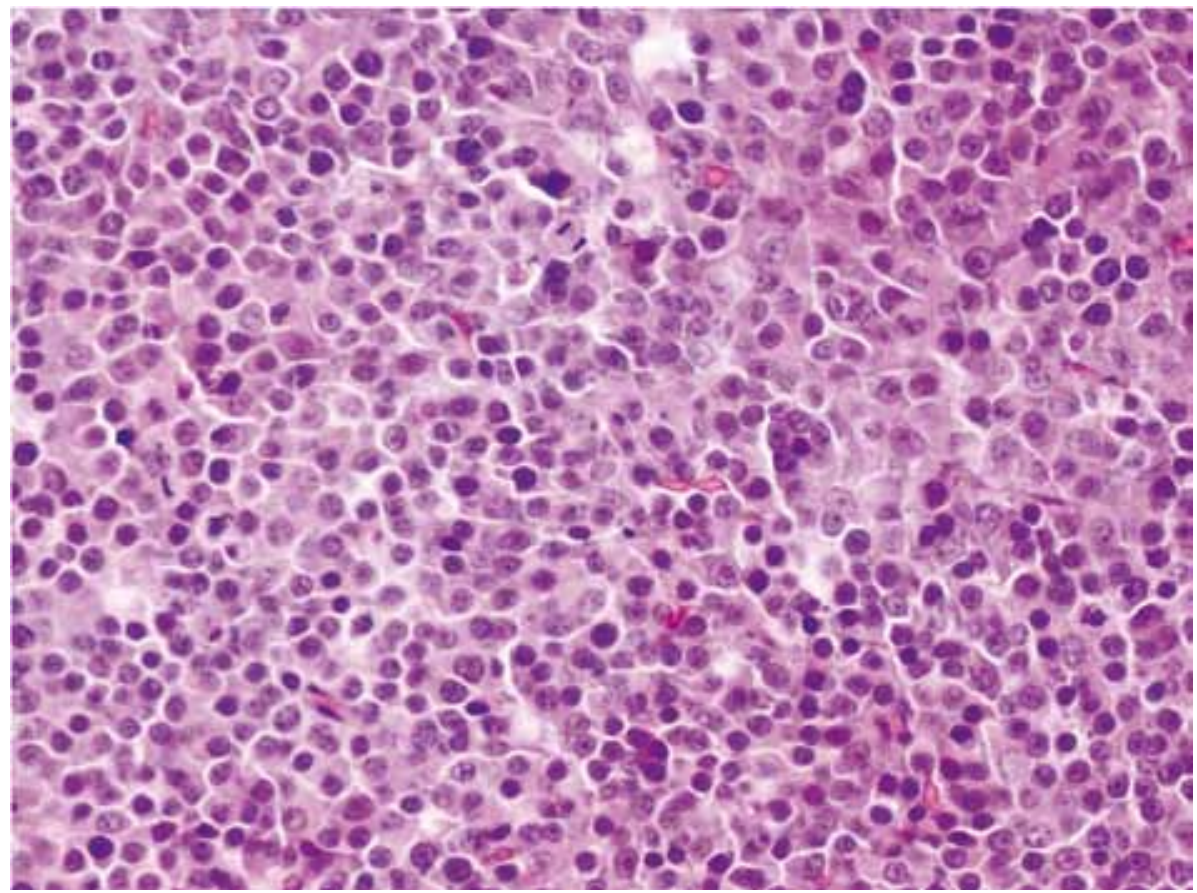

Fig.1. The spleen tissue was replaced by neoplastic tissue, not defined, infiltrating and upsetting the physiological architecture of the organ. The neoplasm was composed of round cells, which were organized in thick layers, divided by fibrous tissue. Their margins were distinct, with an average relationship between the nucleus and cytoplasm, which was slightly basophilic, homogeneous and with vesicular, dysmetric and central nuclei. 